\title{
DETECTION OF UNDERNUTRITION AMONG PRESCHOOL CHILDREN
}

Vaishali Raje ${ }^{1}$, Vinayak Raje ${ }^{2}$, Aditya Punamia ${ }^{3}$, Sanjaykumar S Patil ${ }^{4}$

\section{HOW TO CITE THIS ARTICLE:}

Vaishali Raje, Vinayak Raje, Aditya Punamia,Sanjaykumar S Patil. "Detection of undernutrition among preschool children". Journal of Evolution of Medical and Dental Sciences 2013; Vol2, Issue 48, December 02; Page: 93059309.

ABSTRACT: BACKGROUND: Undernutrition among Indian preschool children is very much prevalent and is the predisposing factor for various types of morbidity and mortality. OBJECTIVES: To detect prevalence of under nutrition among preschool children and to find out sensitive tool for detection of under nutrition. Study design: A cross sectional study. Study subjects: Children of age group below 6 years attending anganwadi. Sample size: Total 108 children attending anganwadi were included in the study. Data collection: Data was recorded in prestructured proforma, consisting information regarding personal data and anthropometric measurements like height, weight, head circumference, mid arm circumference etc. RESULTS: The overall prevalence of undernutrition according to weight for height, body mass index, weight for age by IAP classification and by Kanawati and Mc Laren index was 36.11\%, 41.67\%, 42.59\% and 66.67\%, respectively. Most sensitive tool observed was Kanawati and Mc Laren index to detect true positive undernutrition cases. CONCLUSION: Maximum number of undernutrition cases were detected by Kanawati and Mc Laren index, whose ability of detecting true undernutrition cases is very much high in comparison with other indices, even though the sensitivity to detect normal children and predictive ability is less. So the Kanawati and Mc Laren index is considered superior to detect undernutrition in the community.

KEY WORDS: Anthropometric criteria, ICDS, preschool children, undernutrition

INTRODUCTION: A number of National programs are existing for improvement of nutritional status of children, but undernutrition among Indian children is still prevalent to a large extent. Under 5 children are most vulnerable group for undernutrition and undernutrition is predisposing factor for morbidity like infectious diseases and mortality due to the same. Preschool children constitute about $14 \%$ of total population of India. One out of every ten infant does not reach his $1^{\text {st }}$ birthday, 15 out of 100 children die before they complete five years of age. ${ }^{1}$

Under ICDS, anganwadi worker plays very important role in delivering various services to different beneficiaries. Also she will be engaged in maintaining various registers and paying visits to community may affect the quality of services given by her. If easiest method of detection of malnutrition is available for anganwadi workers, which will be sensitive, it can be utilized in community even at remote places.

Thus to know magnitude of undernutrition among preschool children and to find out sensitive tool for detection of undernutrition this study was conducted among slum children under 5 years of age attending anganwadi.

MATERIAL AND METHOD: This cross sectional study was carried out from Feb 2008 to March 2008 among the children attending anganwadi under ICDS scheme of rural Malkapur area which is field practice area of Krishna Institute of Medical Sciences Karad, Maharashtra. Sample size of 99 (98.56) 


\section{ORIGINAL ARTICLE}

was determined by using formula $\mathrm{n}=4 \mathrm{pq} / \mathrm{L}^{2}$, considering the prevalence of undernutrition among rural preschool children $56 \%^{2}$ with allowable error $10 \%$. For convenience three anganwadis that totaling minimum sample size (after deducting dropouts) were involved in the study. Out of 14 anganwadis, 3 anganwadis were selected by lottery method. Thus sample of 108 was studied from the selected anganwadis as per Table no. 1 .

Anthropometric measurements in the form of height and weight were taken using standard techniques ${ }^{3}$. Height was measured against a meter rod. Body weight was measured using a leveractuated balance in kilograms with an accuracy of 100 grams with minimum clothing. Mid arm circumference was measured on a tape placed gently but firmly around the freely hanging left arm at the midpoint. Head circumference was measured by placing one end of tape on the glabella and placing it around the head over the opisthocranion point and again meeting at glabella. The ages of children were obtained by contacting mothers of respective children. Prestructured proforma was used to record information regarding personal data and anthropometric measurements. Various anthropometric criteria like Body mass index, Kanawati and Mc Laren Index, weight for age according to IAP classification ${ }^{4}$ and weight for height according to Shakir's classification were used to define nutritional status ${ }^{5}$. The definition of undernutrition considered as underweight for age, stunted and wasted according to UNICEF $4,6-9$.

Statistical analysis: $\chi^{2}$ test applied to study agreement between study indices; body mass index, Kanawati and Mc Laren index, weight for age by IAP and standard method; weight for height. In addition to this, sensitivity, specificity and predictive ability of body mass index, Kanawati and Mc Laren Index, weight for age by IAP against weight for height was assessed.

RESULTS: In the current study, total 108 children ( $41.67 \%$ boys and $58.33 \%$ girls) attending anganwadi were interviewed and examined. Maximum children belonged to age group of 5 to 6 years (40.74\%); more than half of children (52.78\%) belonged to joint family and with family size of 5 to 6 in $42.58 \%$ of children. Majority of children (85.19\%) were of birth order $\leq 2$. Illiteracy of mother was observed in $13.85 \%$ children. More than $1 / 3^{\text {rd }}$ children $(36.11 \%)$ belonged to $5^{\text {th }}$ class of modified B.J. Prasad's socioeconomic classification.

Undernutrition with Kanawati and Mc Laren index was 66.67\%. Whereas proportion of undernourished children according to weight for age, body mass index and weight for height criteria $42.59 \%, 41.67 \%$ and $36.11 \%$ respectively (Table II). It was observed that all the indices significantly detected undernutrition (weight for age $p=0.007$, Kanawati and Mc Laren index $p=0.04$, Body mass index $\mathrm{p}=0.01$ ). The varying prevalence of undernutrition by various criteria was found high sensitivity i.e. ability of identification of undernutrition in comparison to standard technique; weight for height was observed by criteria Kanawati and Mc Laren followed by weight for age and body mass index (Table III).

DISCUSSION: By weight for age criteria other study ${ }^{10}$ found very higher proportion of children (61.6\%) were under weight and by weight for height almost similar proportion of wasting (32.9\%) among preschool children in comparison with the present study. Similar to present study in other study ${ }^{11}$ also Kanawati and Mc Laren Index gave high rate of undernutrition than the other criteria studied $(\mathrm{p}=0.04)$. Amongst normal preschool children by weight for height criteria, the proportion 
detected as undernourished by Kanawati and Mc Laren index was 30.56\%. While amongst normal preschool children by weight for age it was $24.08 \%$.

Weight for age is used quiet often for the assessment of nutritional status, but the accurate age of the children may not be known in the field, which leads to limit the use of this index for survey purpose 4 . Weight for height is an age independent index, which reflects acute and present malnutrition. But to know acute on chronic undernutrition weight for height is to be compared with height for age ${ }^{12}$. The body mass index is age independent in preschool children and is significantly co-related with weight, skin fold thickness, arm and calf circumference. Since weight for height indicates current nutritional status, it was taken as an indicator to detect true undernutrition in the community to compare the sensitivity, specificity and predictive value of other criteria (Table: III). Though weight for age had high sensitivity, specificity and predictive value i.e. it was able to diagnose $64.1 \%$ of malnourished and $69.57 \%$ of normal children in the community, it was observed that Kanawati and Mc Laren index has very high ability to detect true undernourished children sensitivity $87.18 \%$ even though the specificity is lowest than weight for age and body mass index and predictive ability also less than weight for age.

CONCLUSION: From current study it is seen that by using Kanawati and Mc Laren index maximum number of undernourished cases were detected. Also the ability of detecting true undernutrition cases was found very much high with Kanawati and Mc Laren index than other indices, even though the sensitivity to detect normal children and predictive ability is less. Therefore Kanawati and Mc Laren index is considered to be a superior index to detect undernutrition in the community.

RECOMMENDATIONS: Kanawati and Mc Laren index is easy to calculate and constant throughout the preschool age. The anthropometric measurements are easy to record and the instrument which is required to record the data i.e. measuring tape is easy to carry for field survey even at remote places. So the tool, Kanawati and Mc Laren index is recommended for the use by the health workers, anganwadi workers and any other investigators in rapid assessment of nutritional status of preschool children in the community or at remote areas.

\begin{tabular}{|c|c|c|c|}
\hline Anganwadi & Subjects involved & Drop outs & Total strength of anganwadi \\
\hline Section I & 35 & 15 & 50 \\
\hline Section II & 30 & 09 & 39 \\
\hline Section III & 43 & 05 & 48 \\
\hline Total & 108 & 29 & 137 \\
\hline \multicolumn{2}{|c|}{ Table 1: Selection of anganwadi to fulfill study sample } \\
\hline
\end{tabular}

\begin{tabular}{|l|c|c|c|c|}
\hline \multicolumn{1}{|c|}{ Criterion } & Normal (\%) & Mild (\%) & Moderate (\%) & Severe (\%) \\
\hline Weight for height & $69(63.89)$ & $35(32.41)$ & $04(3.7)$ & $0(0.0)$ \\
\hline Weight for age (IAP) & $62(57.41)$ & $36(33.33)$ & $08(7.41)$ & $2(1.85)$ \\
\hline Kanawati and Mac Leren index & $36(33.33)$ & $60(55.56)$ & $09(8.33)$ & $3(2.78)$ \\
\hline Body mass index & $63(58.33)$ & $45(41.67)$ & & \\
\hline
\end{tabular}




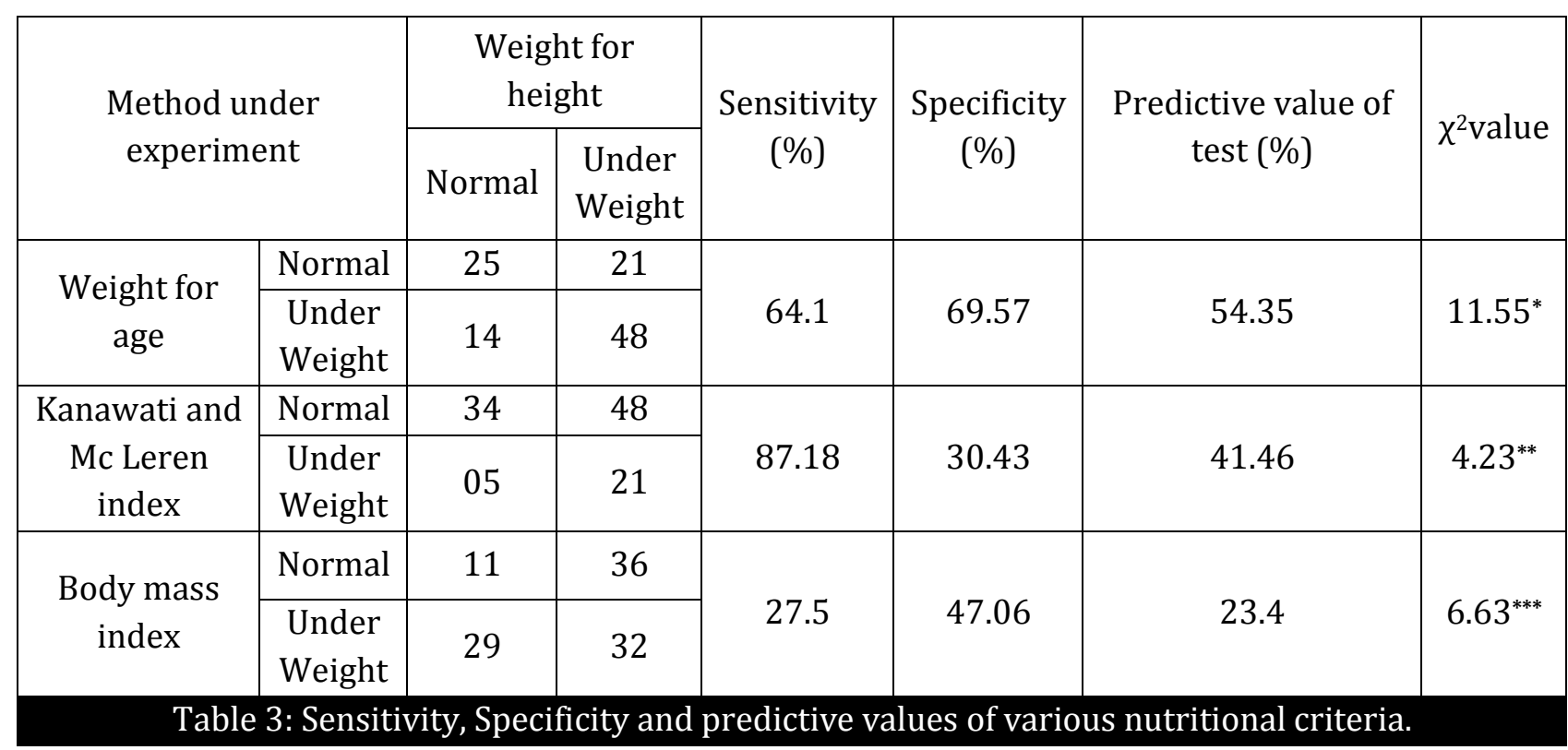

$\mathrm{p}=0.0007^{*}, \mathrm{p}=0.04^{* *}, \mathrm{p}=0.01^{* * *}$

\section{REFERENCES:}

1. Sanjay Karla: 'An Investment In Children's Health, Nutrition \& Education Is The Foundation Stone For All National Development': Indian Journal of Maternal And Child Health: 1991:2 (3): 98.

2. M. S. Tripathi, V. Sharma: Assessment of Nutritional Status of Pre-Schoolers in Slum Areas of Udaipur City: Indian Journal of Public Health: Jan-March: 2006: Vol. 50:1-32.

3. Physical status the use and interpretation of anthropometry: Report of a WHO Expert Committee: WHO TRS: 1995: 854: 1-452.

4. O. P. Ghai: Nutrition and Macronutrient Disorders: Textbook of Pediatrics: CBS publisher: $6^{\text {th }}$ edition: 2005: 101-117.

5. Shakir A: Pattern of protein energy malnutrition in young children attending an out patient clinic in Baghdad: Lancet: 1972: ii: 143-146.

6. http://www.unicef.org/progressforchildern/2006n4/undernutritiondefinition.html

7. Improving child nutrition: The achievable imperative for global progress: unite for children: UNICEF: April 2013.

8. The Lancet's Series on Maternal and Child Undernutrition Executive Summary. The Lancet: 16 January 2008.

9. Richard Horton: Maternal and child undernutrition: an urgent opportunity: The Lancet: Volume 371, Issue 9608, Page 179, 19 January 2008.

10. V. G Rao, Rajeev Yadav, C. K. Dolla, Surendra Kumar, M. K. Bhondeley \& Mahendra Ukey: Undernutrition \& Childhood Morbidities Among Tribal Preschool Children: Indian Journal of Medical Research : July 2005 : 122: 43-44.

11. Ajay K. Sood, Umesh Kapil: Anthropometry in Detection of Protein Energy Malnutrition: Indian Pediatrics: Vol.21: August 1984 


\section{ORIGINAL ARTICLE}

12. K Park: Nutrition and Health: Textbook of Preventive and Social Medicine: M/s Banarsidas Bhanoti Publishers:19th edition: 2007: 507-508.

\section{AUTHORS:}

1. Vaishali Raje

2. Vinayak Raje

3. Aditya Punamia

4. Sanjaykumar S Patil

\section{PARTICULARS OF CONTRIBUTORS:}

1. Associate Professor, Department of Community Medicine, Krishna Institute of Medical Sciences University, Dhebewadi Road, Malkapur, Karad.

2. Consultant, Department of Neurosurgery, Krishna Institute of Medical Sciences University, Dhebewadi Road, Malkapur, Karad.

3. Post Graduate Student, Department of General Surgery, Krishna Institute of Medical Sciences University, Dhebewadi Road, Malkapur, Karad.
4. Associate Professor, Department of OBG, Krishna Institute of Medical Sciences University, Dhebewadi Road, Malkapur, Karad.

\section{NAME ADRRESS EMAIL ID OF THE CORRESPONDING AUTHOR:}

Dr. Vaishali Raje, Department of Community Medicine, Krishna Institute of Medical Sciences, Dhebewadi Road,

Malkapur, Karad.

Email - vaishalinalawade@yahoo.com, metastatic007@gmail.com

Date of Submission: 06/11/2013.

Date of Peer Review: 07/11/2013.

Date of Acceptance: 21/11/2013.

Date of Publishing: 26/11/2013 